\title{
Coulisses
}

Revue de théâtre

12 | Printemps 1995

Varia

\section{Labiche, se divertir sous le Second Empire}

Nella Arambasin

\section{OpenEdition}

Journals

Édition électronique

URL : http://journals.openedition.org/coulisses/3366

DOI : 10.4000/coulisses.3366

ISSN : 2546-9460

\section{Éditeur}

Presses universitaires de Franche-Comté

\section{Édition imprimée}

Date de publication : 1 mai 1995

Pagination : $55-57$

ISSN : 1150-594X

\section{Référence électronique}

Nella Arambasin, «Labiche, se divertir sous le Second Empire », Coulisses [En ligne], 12 | Printemps

1995, mis en ligne le 15 mars 2019, consulté le 27 octobre 2019. URL : http://journals.openedition.org/ coulisses/3366 ; DOI : 10.4000/coulisses.3366

Ce document a été généré automatiquement le 27 octobre 2019

Coulisses 


\title{
Labiche, se divertir sous le Second Empire
}

\author{
Nella Arambasin
}

1 Labiche appartient à une époque qui se soucie de ne pas perdre de temps. Car le milieu $\mathrm{du}$ XIX ème siècle s'empresse à progresser, financièrement propulsé dans les milieux bancaires, politiquement condensé sous les soulèvements populaires, largement stimulé par une vitesse que la technologie ajuste aussi bien aux chemins de fer qu'à la montre individuelle. S'il faut courir, c'est parce que le mouvement vous prend, plus que vous ne prenez le temps.

2 Au théâtre même, les auteurs « fabriquent des pièces comme des industriels " ${ }^{1}$, pour les vendre certes, mais pour qu'elles puissent être rapidement consommées aussi. Il importe qu'elles soient bâties sur une actualité, forcément périssable, et une mode encore tenace du couplet à pointes. Ainsi, c'est le vaudeville qui agence avec le plus de bonheur les idées du moment avec la répétition des airs du temps, comme autant de variations d'un seul et même thème: le rebondissement. Les arrêts ne sont que momentanés, toujours repris par une intrigue de circonstance qui fait montre d'une patiente obstination. Même la révolution de 1848 n'interrompt pas les représentations, et Labiche de se mettre alors à rédiger Un jeune-Homme pressé ${ }^{2}$.

3 Pour Labiche, l'heure est la même que pour tout le monde, mais d'une acuité sans commune mesure. Les aiguilles tournent dans le sens du rattrapage, en retard sur le souhaitable, en avance sur le probable, doublées par une suractivité qui détourne le cours des destinées et les corrige de façon à les déclencher. Le point de départ est déjà un point d'arrivée, et ce que l'on croyait devancer dans l'excitation, n'est qu'un point déplacé par rapport à un autre ordre de grandeur, durable et indifférent. Ce que l'on pensait définitivement perdre, s'accumule de minute en minute, en élaborant à rebours son arithmétique. Les gens dérapent mais rejoignent latéralement leur chemin, ils dérivent mais remontent jusqu'aux origines de la bifurcation.

4 Parce qu'en fait chaque accélération retarde le dénouement, qui en revanche se développe dès les premiers instants, la scansion du vaudeville souligne les espaces entre ce qui pourrait advenir et ce qui n'arrivera jamais : l'impossible révolution qui 
renverserait le temps. Cet espace intermédiaire est un temps limite qui coupe le souffle, sans pour autant arrêter la respiration. "S'arrêter à la limite du scandale " $^{3}$ est un tour de force très certainement, celui qui fait de Labiche l'auteur dramatique le plus lucide du Second Empire, stable époque qui ne pouvait supporter l'idée qu'un grain de sable puisse enrayer son fonctionnement.

C'est pourquoi, chaque fois, la machine s'enraye: le suspens se déploie et l'angoisse surprenante pointe à travers une musique bien connue. D'un air à l'autre, le vagabondage fait aller et venir les circonstances d'une seule et même ronde qui tourne en farandole. Et s'il faut se débattre pour que le dernier refrain regagne le temps que l'on croyait avoir perdu, une fois l'affaire jouée, la perte n'aura été qu'illusoire et d'un bénéfice méritoire : en fin de compte, les personnages n'ont fait que le tour de leur montre, et chaque heure n'a fait que le calcul de leurs escomptes. Ils ont tourné sur eux-mêmes comme seule scène de théâtre et n'ont voyagé qu'à travers les représentations d'une peur qu'ils se donnaient pour spectacle. Aussi, le trouble encombrant de leurs difficultés ne provenait pas d'une menace extérieure, mais de leurs pensées les plus raisonnables sur lesquelles venait de se profiler l'impensable.

Dans Le chapeau de paille d'Italie, au matin de son mariage comme à l'aurore de son

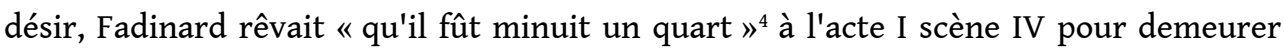
seul avec sa femme. Dès lors, aussi exact que l'horloge qui retranche les segments qui éloignent la promesse de la promise, le cheminement d'une "pensée jamais formulée " $^{5}$ se donne à voir d'actes en actes, aussi redoutable que les obstacles qui reportent et transportent le désir imaginé en cauchemar éveillé. De même que Fadinard vit en différé, d'emblée la vieille fille de La Cagnotte, Léonida attend «que le quart d'heure soit fini $»^{6}$, non pas pour s'éclipser mais entrer dans le jeu des hasards du mariage, où chacun prend successivement la place de l'autre, jusqu'à ce qu'il faille céder son tour et se retrouver à la case départ.

Entre une partie de cartes qui commence et la rencontre d'un chapeau de paille, le destin est tracé de part et d'autre par un mariage qui se prépare. La préparation referme surtout le temps d'un jeu apprêté, d'échange et de substitution, où les êtres font soudain valoir la ressemblance inattendue de leurs rôles. Si tel est le sens de leur bonheur, ne pas être démasqué et de na pas perdre la « face », il leur faut préserver leur place pour ne pas être englouti dans la spirale des similitudes qui les menacent.

Le laps de temps soudain se contracte, réduit à une seule et même expérience. Réduite à une parodie, telle est l'aventure de chacun qui commence un jour et pour toujours. Comme autant de courts-circuits qui illuminent les perspectives conjugales, les liaisons amoureuses sont marquées par la rupture tacite du contrat officiel de mariage. Le quart d'heure tant désiré n'est donc jamais inaugural, car il a déjà été vécu comme un long voyage à travers les intrigues que l'on a fomentées au plus profond de soi.

7 En cortège ou avec ses propres noces aux trousses, il s'agit chaque fois de traverser l'espace intime avec le plus d'assurance possible, alors même que la cohérence du monde s'effondre au passage. C'est la poursuite obsessionnelle d'un objet du désir qui mène la danse selon une commune mesure. Qu'il soit légitime ou illégitime, qu'il se noue ou en dénoue un autre, le couple est désiré. Mais loin d'être une expérience qui se dilate dans le temps, le désire est interrompu et déjà repris ailleurs, parallèlement, selon les variations infinies de la répétition du même. A l'horizon où tout objet prend la forme d'une fuite en avant, les parallèles se rencontrent au lieu qui les ramène sur elles-mêmes. Ce retour dessine le cercle des désirs avoués ou redoutés, cercle des 
embarras qui tentent d'échapper à la répétition pour en finir et en sortir.

La sortie du cercle est en fait impossible et c'est dans la clôture que s'incarne le temps du désir au Second Empire. Avant d'incarcérer littéralement ses acteurs sur scène, Labiche avait bien fait comprendre à son Jeune-Homme pressé que «le vaudeville est l'art de faire dire oui au papa de la demoiselle qui disait non $»^{7}$. La dialectique est imparable, parce qu'elle est socialement maîtrisée et moralement sous-tendue, entre passé et avenir, le temps de toute une vie.

Dialectique en apparence superficielle, elle raconte cependant l'élaboration d'un double discours, progressif et parallèle qui suppose une évolution et un retournement, alors que d'avance, tout est joué, qu'il n'y a qu'un ordre, caché pour les uns, évident pour les autres. Avec l'évidence d'une dépendance filiale, sociale et sexuelle, la fille à marier est l'enjeu d'un contrat à négocier, d'un débat dialogué où l'antithèse cache la thèse, tandis que la thèse passe pour une antithèse cachée.

De l'aparté à l'euphémisme en passant par les malentendus et les quiproquos, le discours théatral cache pour mieux montrer ce qui ne se dit pas, ce qui fait peur ou horreur. En exposant, par le théâtre, les rouages de la dialectique filiale, ce sont les nouages entre hommes et femmes qui s'imposent, comme autant de mensonges sociaux et moraux.

8 Certes « tout le monde sait bien, dans la salle, que ce n'est là qu'un jeu ", mais « sous la farce » le drame est parfois "effroyable $»^{8}$. Si de cet effroi, seul le rire garde la trace, c'est parce que cette trace s'efface au fur et à mesure qu'un éclat de rire en remplace un autre. Les rires et le temps passent si vite que l'on en oublie le sens, l'objet autant que la cause.

Et s'il faut tout de même parler du sens comique, c'est pour l'hypocrisie, l'égoïsme et l'argent qui soudain dans un spasme meurent eux-mêmes de rire. Les bourgeois du Second Empire étaient alors pris à leur piège: «Aucune pitié. L'esprit de Labiche ne leur accorde aucune circonstance atténuante. Ce sont eux qui parlent, qui accusent, se sont eux qui vivent, qui vont vers le châtiment : faire rire " ${ }^{9}$. Il se sont enfin livrés, sans le savoir, avec la générosité et l'inconscience du rire. Ils se sont perdus, dans leur propre divertissement. 


\section{Eugène Labiche}

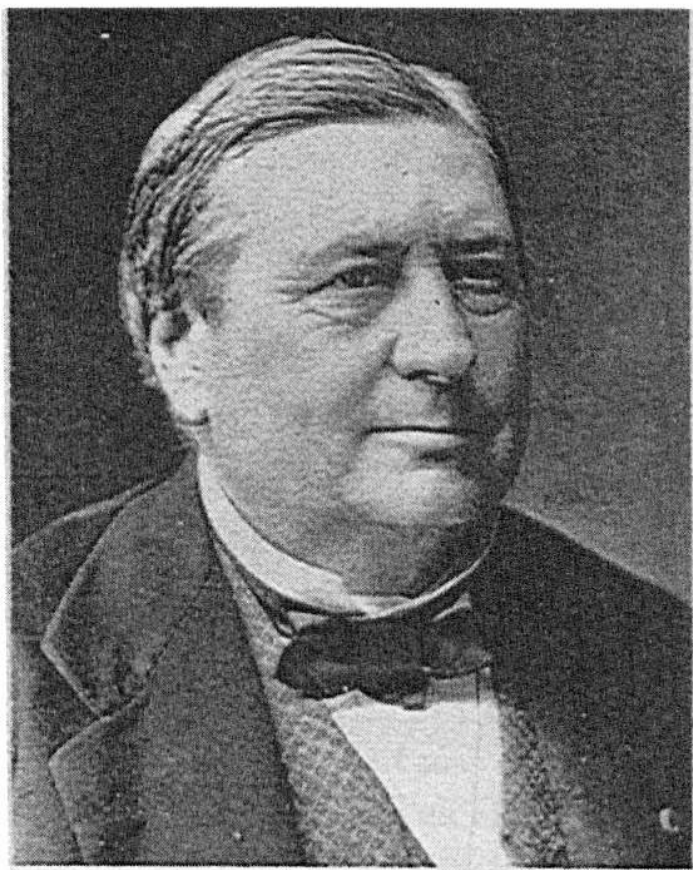

EUGENE LABICHE.

\section{NOTES}

1. Pierre Voltz, La Comédie, Paris, A. Colin, 1964, p. 136.

2. Emmanuel Haymann, Labiche ou l'esprit du Second Empire, Paris, Olivier Orban, 1988, p. 112.

3. Philippe Soupault, Eugène Labiche, Paris, Le sagittaire, 1945, p. 11-17.

4. Labiche, Un Chapeau de paille d'Italie (1851), Paris, Le Livre de poche, 1994, p. 64.

5. Jacqueline Autrusseau, Labiche et son théâtre, Paris, L'Arche, 1971, p. 50.

6. Labiche, La Cagnotte (1864), in Théâtre, Paris, Bordas, 1991-1992, t. III, acte I - scène 1.

7. Labiche cité par E. Haymann, op.cit., p. 112.

8. Zola, « Eugène Labiche », in Nos auteurs dramatiques, Paris, Charpentier, 1904, p. 258.

9. Soupault, op. cit., p. 156. 